\title{
O CRESCIMENTO Do EnSino Superior No Portugal DEMOCRÁTICO: EVOLUÇÃO DA PÓS-GRADUAÇÃO E DA PRODUÇÃO CIENTÍFICA
}

\author{
Portuguese Higher Education growth: eVolution of \\ POSTGRADUATION AND SCIENTIFIC PRODUCTION
}

\section{Luísa Cerdeira}

Doutora em Ciências da Educação pela FPCE da Universidade de Lisboa, Portugal, Professora Auxiliar, UIDEF, Instituto de Educação, Universidade de Lisboa ORCID: https://orcid.org/0000-0002-2217-7822

luisa.cerdeira@ie.ulisboa.pt

\section{Belmiro Gil Cabrito}

Doutor em Ciências da Educação pela FPCE da Universidade de Lisboa, Portugal, Professor Associado Aposentado, UIDEF, Instituto de Educação, Universidade de Lisboa ORCID: http://orcid.org/0000-0003-0420-5639

b.cabrito@ie.ulisboa.pt

\section{Pedro Ribeiro Mucharreira}

Doutor em Educação pelo Instituto de Educação da Universidade de Lisboa, Portugal, Professor Auxiliar Convidado, UIDEF, Instituto de Educação, Universidade de Lisboa ORCID: http://orcid.org/0000-0003-0059-0576 prmucharreira@ie.ulisboa.pt

Resumo: De entre as inúmeras alteraçóes que Portugal conheceu decorrentes da Revoluçáo de Abril, as educativas foram avassaladoras. Desde 1974 assistiu-se a mudanças significativas em todo o edifício educativo, nomeadamente o estabelecimento de uma escolaridade obrigatória e um ensino básico e secundário unificado, a explosão da procura de educação, a criação do ensino superior politécnico, a privatização do ensino superior, a promoção da investigação científica, a ratificação da Declaração de Bolonha ou novas leis de financiamento e de governo e autonomia das instituiçóes públicas de ensino superior. No quadro do ensino superior, a adoção da Declaração de Bolonha obrigou a grandes alteraçóes do enquadramento jurídico da estrutura da formaçáo superior dos países que a ratificaram e, no caso português, concretizou-se num enorme crescimento da pós-graduação e do número de diplomados. Neste artigo, os autores sustentam a sua análise com recurso às estatísticas oficiais de Portugal e de organismos internacionais, analisando a expansão da pós-graduação e da investigação, particularmente no quadro pós-Bolonha. Apresenta-se, ainda, o caminho percorrido pelo sistema científico português e contextualiza-se a situação portuguesa no quadro internacional. Terminarse-á o artigo com algumas reflexóes que poderão ajudar a formular políticas públicas conducentes à melhoria do estado do ensino superior público em Portugal, mormente no financiamento da pós-graduação e da produção científica.

Palavras-chave: Declaração de Bolonha. Ensino Superior. Financiamento. Investigação Científica. 
AвSTRACT: Among the many changes that Portugal knew from the April Revolution, the educational ones were overwhelming. Since 1974, there have been significant changes in the whole educational system, namely the establishment of compulsory schooling and unified middle and high school education, the explosion of demand for education, the creation of polytechnic higher education, the privatization of higher education, promotion of scientific research, ratification of the Bologna Declaration or new laws on funding and governance and autonomy of public higher education institutions. In the framework of higher education, the adoption of the Bologna Declaration has led to major changes in the legal framework of the structure of higher education in the countries that have ratified it, and in the Portuguese case, it has resulted in enormous growth in postgraduate studies and in the number of graduates. In this article, the authors support their analysis using official statistics from Portugal and international organizations, analyzing the expansion of postgraduate and research, particularly in the post-Bologna context. It is also presented the path taken by the Portuguese scientific system and contextualizes the Portuguese situation in the international context. The article will be finished with some reflections that may help to formulate public policies conducive to improving the state of public higher education in Portugal, especially in the financing of postgraduate and scientific production.

Keywords: Bologna Declaration. Higher Education. Financing. Scientific Research.

\section{Introdução}

Nas últimas décadas, Portugal testemunhou inúmeras mudanças de natureza política que trouxeram a democratização do país. Depois de 48 anos de ditadura, a Revoluçáo de Abril de 1974 marcou a mudança. O processo de democratização trouxe, entre outras realidades, a implementação de um estado previdência e o consumo em massa de bens e serviços públicos dos quais a educação é exemplo paradigmático.

De facto, de entre as inúmeras alteraçóes que Portugal conheceu decorrentes da Revolução Democrática de 25 de Abril de 1974, as educativas foram avassaladoras e que se podem "resumir" em dois factos incontroversos: a explosão da procura social de educação, em todos os níveis educativos e a resposta do sistema educativo a essa procura. Após 48 anos de ditadura durante a qual o acesso à educação para a maioria da populaçáo era quase impossível, os portugueses viveram a Revolução, educando-se.

O Quadro 1 apresenta os números que demonstram a natureza explosiva da procura de educação, em todos os níveis educativos, evidenciando a vontade de um país consciente do papel da educação no desenvolvimento (LOPES, 2013; PSACHAROPOULOS; WOODHALL, 1985). 


\begin{tabular}{|c|c|c|c|c|c|c|c|c|}
\hline \multirow{2}{*}{ Anos } & \multirow{2}{*}{ Total } & \multirow{2}{*}{$\begin{array}{l}\text { Educação } \\
\text { Pré-escolar }\end{array}$} & \multicolumn{4}{|c|}{ Ensino Básico } & \multirow{2}{*}{$\begin{array}{c}\text { Ensino } \\
\text { Secundário }\end{array}$} & \multirow{2}{*}{$\begin{array}{l}\text { Ensino } \\
\text { Superior }\end{array}$} \\
\hline & & & Total & $1^{\circ}$ Ciclo & $2^{\circ} \mathrm{Ciclo}$ & $3^{\circ}$ Ciclo & & \\
\hline 1961 & $1110264^{*}$ & 6528 & 1066471 & 887235 & 78064 & 101172 & 13116 & $24149^{* *}$ \\
\hline 1970 & $1407921^{*}$ & 15153 & 1316279 & 935453 & 193912 & 186914 & 27028 & $49461^{* *}$ \\
\hline 1980 & 1873559 & 80373 & 1538389 & 927852 & 305659 & 304878 & 169516 & 80919 \\
\hline 1990 & 2160180 & 161629 & 1531114 & 715881 & 370607 & 444626 & 309568 & 157869 \\
\hline 2000 & 2260745 & 228459 & 1240836 & 539943 & 276529 & 424364 & 417705 & 373745 \\
\hline 2005 & 2172853 & 259788 & 1153057 & 504412 & 267742 & 380903 & 376896 & 380937 \\
\hline 2010 & 2406098 & 274387 & 1256462 & 479519 & 273248 & 503695 & 483982 & 383627 \\
\hline 2015 & 2061813 & 264660 & 1041698 & 418145 & 238582 & 384971 & 393618 & 349658 \\
\hline 2016 & 2027483 & 259850 & 1013397 & 408041 & 230842 & 374514 & 391538 & 356399 \\
\hline 2017 & 2020494 & 253959 & 1000006 & 404010 & 225794 & 370202 & 399775 & 361943 \\
\hline
\end{tabular}

Quadro 1: Evolução da procura de educação, em Portugal, em todos os níveis educativos entre 1961 e 2017

*calculado pelos autores; ${ }^{* *}$ Barreto (1996)

Fonte: DGO/MF, PORDATA (Última atualização: 2018-07-02).

Apesar do indesmentível crescimento da procura de educação, cumpre registar a quebra que se reconhece nessa procura na última década para o que terá concorrido particularmente dois fatores:

- a crise demográfica, que se traduz no facto de Portugal ser um dos países mais envelhecidos e que apresenta as menores taxas de natalidade e de fecundidade na Europa;

- a crise económica e financeira global de 2008 que, em Portugal, se concretizou num "pedido de resgate" a instâncias monetárias internacionais (Banco Central Europeu, União Europeia, Fundo Monetário Internacional) que impuseram fortíssimas políticas de austeridade conduzidas pelo governo liberal em funções e se traduziram numa forte diminuição do investimento público, no despedimento de milhares de funcionários públicos, na falência de milhares de empresas bem como na quebra de rendimentos na máo dos trabalhadores em geral com consequências na procura interna, nomeadamente na procura de educação superior. 
Naturalmente, a democracia instalada em 1974 respondeu à explosão da procura de educação, através de importantes alterações no edifício educacional português. De entre as inúmeras alteraçóes do/no sistema no sentido de responder àquela procura destacam-se, nomeadamente:

- o estabelecimento de um ensino básico (ensino fundamental) e secundário (ensino médio) unificado para os jovens de idades compreendidas entre os 6 e os 17 anos, rompendo com a educação elitista que caracterizou o país até 1974 (MÓNICA, 1978) e que reproduzia as desigualdades sociais (BOURDIEU; PASSERON, 1964, 1970; BAUDELOT; ESTABLET, 1971, 1977; BOUDON, 1973) ao disponibilizar o ensino liceal destinado a preparar os "herdeiros" para a universidade e o ensino técnico (comercial e industrial) frequentado por jovens em geral oriundos dos estratos portadores de menor capital cultural e que os preparava para funçôes executivas no mercado de trabalho, assim assegurando a reprodução do status quo;

- o estabelecimento da escolaridade obrigatória, sucessivamente de 6, 9 e 12 anos, respetivamente em 1974, 1986 e 2008, alteração de primordial importância para uma população com elevados níveis de analfabetismo que queria educar-se e que acreditava na educação como instrumento fundamental de desenvolvimento e de democratização; na verdade, se no final dos anos de 1970 Portugal tinha uma taxa de analfabetismo de cerca de $50 \%$, hoje tem um valor que náo chega aos $5 \%$ e que cobre basicamente a população idosa (PORDATA, 2019); de registar, todavia, que, no que respeita ao ensino superior, uma análise das políticas públicas de financiamento deste nível de ensino e da origem social de estudantes que o frequentam, permitem questionar a hipótese de o ensino superior se ter realmente democratizado (CABRITO; CERDEIRA, 2018; CABRITO et al., 2019);

- a criação de uma nova via de ensino superior, o ensino superior politécnico que passou a ser disponibilizado com o ensino universitário bem como a criação de 7 universidades públicas e de 15 institutos politécnicos públicos de ensino superior, a partir de meados da década de 1970; 
- a formação científica e académica de milhares de docentes do ensino não superior e superior e a promoçáo da investigaçáo científica contando, em grande parte, com o apoio financeiro da União Europeia através do programa PRODEP - Programa de Desenvolvimento da Educação em Portugal (a partir do ano de 1990);

- a produção de legislação visando, nomeadamente, novas formas de governo e de financiamento das instituiçóes públicas de ensino superior e a garantia da sua autonomia administrativa, académica, científica e financeira (Lei da Autonomia Académica de 1988, Leis de Financiamento de 1993, 1997 e 2003, RJIES de 2007), bem como a abertura do ensino superior à iniciativa privada a partir de 1986;

- a ratificação da Declaração de Bolonha, em 1999 e sua implementação a partir de 2006, que pretendia promover a livre circulação e alargar a mobilidade dos estudantes de estudos superiores no Espaço Europeu de Ensino Superior ao "abolir" os títulos académicos e estabelecer um sistema de créditos transferíveis e acumuláveis reconhecidos pelos signatários (ECTS) bem como as exigências daquela implementação constantes na Estratégia de Lisboa (ANTUNES et al., 2018).

A adoção da Declaração de Bolonha obrigou a grandes alteraçóes do enquadramento jurídico da estrutura da formação superior dos países que a ratificaram nomeadamente na sua estrutura. Nos anos anteriores à adoção da Declaração de Bolonha, o ensino superior em Portugal estruturavase da seguinte forma:

- licenciatura, com a duração genérica de 4/5 anos (alguns cursos, como medicina, medicina veterinária, agronomia, arquitetura, advocacia, tinham uma duração de 6 ou mais anos);

- mestrado, com a duração de 3 anos;

- doutoramento, praticamente sem duração explicitada.

Para além dos cursos/diplomas acima apresentados, havia ainda "cursos superiores curtos", cursos oferecidos pelos institutos superiores politécnicos; eram cursos com a duração de $2 / 3$ anos que concediam o diplo- 
ma de "bacharel". Aquando da implementação da Declaração de Bolonha estes cursos encontravam-se já em extinção.

Com a Declaração de Bolonha, no caso português, o ensino superior passou a concretizar-se em três ciclos de estudos:

- $1^{\text {o }}$ ciclo, de graduação, com a duraçáo de 3 anos, ao qual correspondem 180 créditos (60 por ano de estudos de ensino superior) e atribui o diploma de graduado;

- $2^{\circ}$ e $3^{\circ}$ ciclos de pós-graduação; o $2^{\circ}$ ciclo, com a duração de 2 anos, ao qual correspondem 120 créditos e atribui o título de mestre; o $3^{\circ}$ ciclo, com a duração mínima de 3 anos, atribui o título de doutor.

No que respeita aos cursos de mestrado, é de salientar que em algumas situaçôes o mestrado é obrigatório para o exercício da profissão (caso dos professores do ensino não superior, psicólogos, médicos, advogados, etc.), dando origem ao denominado "mestrado integrado" (MUCHARREIRA et al., 2018). Nos restantes casos, os $1^{\circ}$ e $2^{\circ}$ ciclos são "independentes", isto é, existe uma profissáo/carreira profissional para os portadores do $1^{\circ}$ ciclo do ensino superior pelo que a realização de mestrado nessa área depende da decisão voluntária do estudante. Aliás, findo o $1^{\circ}$ ciclo do ensino superior, os estudantes podem candidatar-se a um mestrado em área científica diferente da sua anterior formaçáo, assim alargando as suas possibilidades no mercado de trabalho.

Apesar de os jovens poderem entrar no mercado de trabalho apenas com o diploma de graduação, a contínua exigência de qualificações superiores pelo mercado e a garantia de condiçóes de empregabilidade justifica o prosseguimento generalizado de estudos pelos estudantes após terminarem a graduação, explicando o aumento vertiginoso do número de mestres nas últimas décadas, como de seguida se irá mostrar.

Do exposto pode, assim, afirmar-se que nos últimos anos no Portugal Democrático muito se tem caminhado no intuito de responder à procura de educação e à necessidade de dotar o país de mão de obra altamente qualificada e de se aproximar dos níveis de desenvolvimento dos países mais desenvolvidos da Europa (CABRITO; CERDEIRA, 2018).

Neste artigo, os autores dão conta da evolução que o sistema de ensino português conheceu nas últimas décadas, particularmente de nível 
superior, e situam, sempre que possível, Portugal no quadro internacional partindo de uma análise às estatísticas oficiais de Portugal e de organismos internacionais no sentido de analisarem a expansão da pós-graduação e da investigação, particularmente no quadro pós-Bolonha, bem como a diminuição do financiamento público do ensino superior público, decorrente do facto de o Estado passar a financiar, basicamente, apenas o nível de graduação (1..$^{\circ}$ ciclo) pois o $2^{\circ}$ ciclo, como acima se referiu não é, em geral, exigido pelo mercado para o exercício da profissáo, o que permite questionar até que ponto a Declaração de Bolonha não terá tido, também, razóes marcadamente económicas (CABRITO, 2005; CABRITO, CERDEIRA 2008; CERDEIRA, 2009).

É intenção dos autores ainda apresentar o caminho percorrido pelo sistema científico português, contextualizando a situação do país no âmbito da União Europeia. O artigo terminará com algumas reflexôes que, poderão ajudar a formular políticas públicas conducentes à melhoria do estado do ensino superior público em Portugal, mormente no financiamento da pós-graduação e da produção científica.

\section{Evoluçáo do número de diplomados de nível superior, 1995-2017}

O Quadro 2 apresenta a evolução do número de graduados e de pósgraduados nas últimas décadas, em Portugal.

As informaçôes do Quadro 2 permitem perceber a forma como evoluíram os cursos de graduação e pós-graduação em Portugal, entre 1995 e 2017. Em primeiro lugar, destaque-se o crescimento significativo do número de graduaçóes e de pós-graduações, no período. Em 2017, esse número era mais do que o dobro do número correspondente em 1995, mesmo tendo em conta o decréscimo que se observa nos últimos anos e que acompanhou a crise económica e financeira que assolou o país e que só depois de 2015 parece estar a diminuir de intensidade.

Por outro lado, e decorrente da implementação da Declaração de Bolonha, destaque-se a descontinuidade dos cursos de bacharelato e das licenciaturas pré-Bolonha, surgindo a partir de 2007 os primeiros graduados nas licenciaturas pós-Bolonha e nos mestrados integrados. De salientar, 


\begin{tabular}{|c|c|c|c|c|c|c|c|}
\hline Anos & $\begin{array}{l}\text { Total } \\
\left(\mathrm{N}^{\circ}\right)\end{array}$ & $\begin{array}{l}\text { Bacharelato } \\
\left(\mathrm{N}^{\circ}\right)\end{array}$ & $\begin{array}{l}\text { Licenciatura } \\
\left(\mathrm{N}^{\circ}\right)\end{array}$ & $\begin{array}{c}\text { Licenciatura } \\
\text { Pós-Bolonha } \\
\left(1 .^{\circ} \text { Ciclo }\right) \\
\left(\mathrm{N}^{\circ}\right)\end{array}$ & $\begin{array}{c}\text { Mestrado } \\
\text { Integrado } \\
\left(2 .^{\circ} \text { Ciclo }\right) \\
\left(N^{\circ}\right)\end{array}$ & $\begin{array}{c}\text { Mestrado } \\
\left(\mathrm{N}^{\circ}\right)\end{array}$ & $\begin{array}{l}\text { Doutora- } \\
\text { mento }\left(3 .^{\circ}\right. \\
\text { Ciclo })\left(\mathrm{No}^{\circ}\right)\end{array}$ \\
\hline 1995 & 35.939 & 10.311 & 21.695 & 11 & II & 1.407 & $X$ \\
\hline 1996 & 39.216 & 10.756 & 23.561 & II & II & 1.704 & $\mathrm{X}$ \\
\hline 1997 & 42.796 & 11.120 & 25.067 & /I & /I & 1.884 & 232 \\
\hline 1998 & 46.478 & 12.172 & 27.254 & II & /I & 2.117 & 375 \\
\hline 1999 & 51.336 & 12.732 & 31.492 & 11 & /I & 1.979 & 379 \\
\hline 2000 & 54.255 & 12.169 & 33.958 & II & /I & 1.953 & 551 \\
\hline 2001 & 61.140 & 11.465 & 36.273 & II & 11 & 2.207 & 585 \\
\hline 2002 & 64.098 & 10.626 & 39.179 & II & /I & 2.326 & 665 \\
\hline 2003 & 68.511 & 10.897 & 43.394 & 11 & 11 & 2.885 & 838 \\
\hline 2004 & 68.668 & 12.155 & 43.886 & II & II & 3.068 & 895 \\
\hline 2005 & 69.987 & 13.035 & 45.771 & II & II & 3.152 & 998 \\
\hline 2006 & 71.828 & 12.762 & 47.131 & /I & II & 4.248 & 1.094 \\
\hline 2007 & 83.276 & 8.748 & 42.939 & 19.061 & 984 & 5.323 & 1.269 \\
\hline 2008 & 84.009 & 3.230 & 24.485 & 40.010 & 4.831 & 6.274 & 1.285 \\
\hline 2009 & 76.567 & 762 & 12.426 & 42.514 & 6.782 & 9.369 & 1.267 \\
\hline 2010 & 78.609 & 19 & 2.853 & 50.727 & 7.029 & 12.515 & 1.414 \\
\hline 2011 & 78.785 & 3 & 237 & 51.267 & 7.420 & 14.733 & 1.608 \\
\hline 2012 & 81.410 & 1 & 46 & 50.906 & 7.797 & 18.367 & 1.859 \\
\hline 2013 & 80.899 & $/ /$ & 3 & 51.467 & 7.698 & 17.316 & 2.463 \\
\hline 2014 & 75.906 & /I & 1 & 47.592 & 7.831 & 16.202 & 2.503 \\
\hline 2015 & 76.892 & /I & $/ /$ & 47.194 & 8.166 & 16.746 & 2.351 \\
\hline 2016 & 73.086 & /I & /I & 46.522 & 8.469 & 15.553 & 2.344 \\
\hline 2017 & 77.034 & $/ /$ & $/ /$ & 47.280 & 8.386 & 16.020 & 2.135 \\
\hline
\end{tabular}

Quadro 2: Evolução do número de graduados e de pós-graduados, em Portugal, entre 1995 e 2017

Fonte: Pordata (2018) (elaboração dos autores).

também, o aumento do número de mestres. Aliás, é interessante registar que o número total de mestres (integrados e não integrados) aumentou de forma significativa na sua relação com o número de diplomados do $1^{\circ}$ ciclo, revelando uma procura crescente de qualificação académica. Observese os valores do Quadro 3. 


\begin{tabular}{|c|c|c|}
\hline & 2007 & 2017 \\
\hline No de Licenciados (1) & 62000 & 47280 \\
\hline No de Mestres (2) & 6307 & 24406 \\
\hline No de Mestres/No de Licenciados*100 & 10,2 & 51,6 \\
\hline
\end{tabular}

Quadro 3: Peso do número total de mestres no número total de licenciados, em 2007 e 2017, em percentagem

(1) Somatório dos licenciados das licenciaturas antes de Bolonha e pós-Bolonha

(2) Somatório dos mestrados integrados e não integrados

Fonte: Pordata (2018), elaboração dos autores.

O Quadro 3 mostra bem a procura de habilitaçóes superiores por parte dos estudantes portugueses, ao longo da década sendo que em 2007 o número de mestrados ascendia a $10,2 \%$ do número de licenciados e que essa percentagem já é de 51,6\% em 2017, isto é, o número de mestres registado nas duas datas, quadruplicou e o seu peso em relação ao número de diplomados do $1^{\circ}$ ciclo, quintuplicou.

Os dados permitem afirmar que a procura de habilitações superiores é uma realidade efetiva nas últimas décadas em Portugal. Todavia, pode argumentar-se que o ritmo intenso de crescimento dos mestrados decorre, não de uma maior procura de educação superior, mas da necessidade de os jovens que terminam atualmente o $1^{\mathrm{o}}$ ciclo prosseguirem estudos pelo facto de esse ciclo ter uma duração bastante menor ( 3 anos) do que as licenciaturas pré-Bolonha ( $4 / 5$ anos, em geral). $\mathrm{O}$ mestrado, assim, seria a forma de os diplomados se apresentarem no mercado com um número maior de anos de ensino superior, como se o mestrado atual fosse equivalente às anteriores licenciaturas em número de anos de educação de nível superior.

A fim de se perceber a validade daquele argumento, analisou-se a evolução dos cursos de licenciatura e de mestrado ao longo do mesmo período, procurando perceber se existiria uma transferência líquida dos licenciados para os mestrados ou para os novos mestrados integrados. Observe-se o Quadro 4. 


\begin{tabular}{|c|c|c|c|c|}
\hline Anos & $\begin{array}{c}\text { Licenciatura } \\
\text { (Pré e Pós- } \\
\text { Bolonha) (No) }\end{array}$ & $\begin{array}{c}\text { Taxas de } \\
\text { Variação - } \\
\text { Licenciaturas } \\
(\%)\end{array}$ & $\begin{array}{c}\text { Mestrado (Pré } \\
\text { e Pós-Bolonha) } \\
(\text { No) }\end{array}$ & $\begin{array}{c}\text { Taxas de } \\
\text { Variação- } \\
\text { Mestrados (\%) }\end{array}$ \\
\hline $\mathbf{1 9 9 5}$ & 21.695 & - & 1.407 & - \\
\hline $\mathbf{1 9 9 6}$ & 23.561 & 8,60 & 1.704 & 21,11 \\
\hline $\mathbf{1 9 9 7}$ & 25.067 & 6,39 & 1.884 & 10,56 \\
\hline $\mathbf{1 9 9 8}$ & 27.254 & 8,72 & 2.117 & 12,37 \\
\hline $\mathbf{1 9 9 9}$ & 31.492 & 15,55 & 1.979 & $-6,52$ \\
\hline $\mathbf{2 0 0 0}$ & 33.958 & 7,83 & 1.953 & $-1,31$ \\
\hline $\mathbf{2 0 0 1}$ & 36.273 & 6,82 & 2.207 & 13,01 \\
\hline $\mathbf{2 0 0 2}$ & 39.179 & 8,01 & 2.326 & 5,39 \\
\hline $\mathbf{2 0 0 3}$ & 43.394 & 10,76 & 2.885 & 24,03 \\
\hline $\mathbf{2 0 0 4}$ & 43.886 & 1,13 & 3.068 & 6,34 \\
\hline $\mathbf{2 0 0 5}$ & 45.771 & 4,30 & 3.152 & 2,74 \\
\hline $\mathbf{2 0 0 6}$ & 47.131 & 2,97 & 4.248 & 34,77 \\
\hline $\mathbf{2 0 0 7}$ & 62.000 & 31,55 & 6.307 & 48,47 \\
\hline $\mathbf{2 0 0 8}$ & 64.495 & 4,02 & 11.105 & 76,07 \\
\hline $\mathbf{2 0 0 9}$ & 54.940 & $-14,82$ & 16.151 & 45,44 \\
\hline $\mathbf{2 0 1 0}$ & 53.580 & $-2,48$ & 19.544 & 21,01 \\
\hline $\mathbf{2 0 1 1}$ & 51.504 & $-3,87$ & 22.153 & 13,35 \\
\hline $\mathbf{2 0 1 2}$ & 50.952 & $-1,07$ & 26.164 & 18,11 \\
\hline $\mathbf{2 0 1 3}$ & 51.470 & 1,02 & 25.014 & $-4,40$ \\
\hline $\mathbf{2 0 1 4}$ & 47.593 & $-7,53$ & 24.033 & $-3,92$ \\
\hline $\mathbf{2 0 1 5}$ & 47.194 & $-0,84$ & 24.912 & 3,66 \\
\hline $\mathbf{2 0 1 6}$ & 46.522 & $-1,42$ & 24.022 & $-3,57$ \\
\hline $\mathbf{2 0 1 7}$ & 47.280 & 1,63 & 24.406 & 1,60 \\
\hline & & & & \\
\hline
\end{tabular}

Quadro 4: Evolução e Ritmo de Crescimento das Licenciaturas e Mestrados Pré e Pós-Bolonha, em Portugal, 1995-2017

Fonte: Elaboração própria - dados obtidos em Pordata (2018).

A partir da análise dos valores do Quadro 4 é possível perceber que o Processo de Bolonha terá potenciado um forte crescimento da con- 
clusão de licenciaturas e mestrados, mas de forma mais evidente entre 2006 e 2013. A partir de 2013, e muito provavelmente também justificado pelas fortes medidas de austeridade que se vivenciaram em Portugal, a conclusão destes níveis foi decrescendo gradualmente. De notar que em 2017 o número de licenciados se fixava na ordem dos $47 \mathrm{mil}$, precisamente o mesmo valor registado em 2006.

Relativamente aos mestrados, verificaram-se taxas de crescimento bastante acentuadas, explicadas em grande medida pelo prosseguimento de estudos dos alunos de licenciatura que, com a Declaração do Bolonha, passaram a ter a possibilidade de concluir este nível em 3 anos (para a generalidade dos cursos).

Todavia, a diferença do ritmo de crescimento das licenciaturas e dos mestrados, sendo o dos mestrados grande e positivo, mesmo em anos em que a taxa de crescimento das licenciaturas foi negativa, evidencia uma procura crescente de qualificaçóes superiores que não é, apenas, consequência direta da diminuição do número de anos para concluir uma licenciatura. Os dados não provam, pois, que exista uma transferência líquida da licenciatura para o mestrado pelo que parece lícito aceitar o voluntarismo que caracteriza a procura de qualificaçóes superiores em Portugal Democrático.

No entanto, os números mostram claramente que as quebras na procura de ensino superior, $1^{\circ}$ e $2^{\circ}$ ciclos acompanharam as políticas de austeridade que assolaram o país e que implicaram uma quebra enorme do poder de compra das populaçóes.

Aliás, o mesmo aconteceu com a diplomação doutoral, sendo de sublinhar que também a conclusão de doutoramentos tem apresentado uma clara tendência decrescente nos anos da crise económica e financeira do país e correspondentes políticas de austeridade. Observe-se o Quadro 5.

Como se pode perceber, também ao nível dos doutoramentos, nota-se uma contração recente do número de doutoramentos que é mais evidente a partir de 2014 mas que é já uma realidade quando se comparam as taxas médias de crescimento do número de doutorados antes e depois da crise. De facto, enquanto que entre 1997 e 2006 houve um crescimento médio de doutoramentos na ordem dos 20,2\% ao ano, entre 2006 e 2017 esse valor ficou-se pelos 7,1\%. Comparando diretamente os 


\begin{tabular}{|c|c|c|c|c|}
\hline Anos & $\begin{array}{l}\text { Doutoramento } \\
\left(3 .^{\circ} \text { Ciclo) (No) }\right.\end{array}$ & $\begin{array}{c}\text { Taxas de } \\
\text { Variaçáo (\%) }\end{array}$ & $\begin{array}{c}\text { Taxas de } \\
\text { Variaçáo } \\
\text { Média 1997- } \\
2006 \text { e 2006- } \\
2017(\%)\end{array}$ & $\begin{array}{c}\text { Taxas de } \\
\text { Variaçáo } \\
\text { 1997-2006 e } \\
2006-2017(\%)\end{array}$ \\
\hline 1995 & $\mathrm{x}$ & - & \multirow{11}{*}{$20,2 \%$} & \multirow{11}{*}{$371,6 \%$} \\
\hline 1996 & $\mathrm{x}$ & - & & \\
\hline 1997 & 232 & - & & \\
\hline 1998 & 375 & 61,6 & & \\
\hline 1999 & 379 & 1,1 & & \\
\hline 2000 & 551 & 45,4 & & \\
\hline 2001 & 585 & 6,2 & & \\
\hline 2002 & 665 & 13,7 & & \\
\hline 2003 & 838 & 26 & & \\
\hline 2004 & 895 & 6,8 & & \\
\hline 2005 & 998 & 11,5 & & \\
\hline 2006 & 1.094 & 9,6 & & \\
\hline 2007 & 1.269 & 16 & \multirow{11}{*}{$7,1 \%$} & \multirow{11}{*}{$95,2 \%$} \\
\hline 2008 & 1.285 & 1,3 & & \\
\hline 2009 & 1.267 & $-1,4$ & & \\
\hline 2010 & 1.414 & 11,6 & & \\
\hline 2011 & 1.608 & 13,7 & & \\
\hline 2012 & 1.859 & 15,6 & & \\
\hline 2013 & 2.463 & 32,5 & & \\
\hline 2014 & 2.503 & 1,6 & & \\
\hline 2015 & 2.351 & $-6,1$ & & \\
\hline 2016 & 2.344 & $-0,3$ & & \\
\hline 2017 & 2.135 & $-8,9$ & & \\
\hline
\end{tabular}

Quadro 5: Evolução e Ritmo de Crescimento dos Doutoramentos Pré e Pós-Bolonha, em Portugal, 1995-2017

Fonte: Elaboração própria - dados obtidos em Pordata (2018). 
doutorados em 2006 com os verificados em 1997 e realizando a mesma taxa de variação entre 2006 e 2017, constata-se, respetivamente, um crescimento na ordem dos $372 \%$ e $95 \%$ denunciando uma quebra substantiva no número de doutoramentos no segundo período.

\section{Evolução da Investigação e da produção científica em Portugal, 1995-2017}

\subsection{Evolução do número de investigadores e da produção científica, 1995-2015}

Do exposto ficou claro que nas últimas décadas a procura de educação de nível superior e as taxas de conclusão dos três ciclos de ensino superior em Portugal, aumentou de forma continuada e significativa, excetuando-se o período de crise económica e financeira que terá conhecido uma inversão da tendência após 2015.

Todavia, o desenvolvimento do país bem como a melhoria da qualidade da educação disponibilizada exige o desenvolvimento da investigação científica. Por esse facto, é importante perceber como tem evoluído a investigação científica no país, bem como conhecer os setores que conduzem essa atividade. Nesse sentido, apresentam-se, de seguida, alguns indicadores que podem esclarecer acerca do volume e qualidade da investigação científica no país, nas últimas décadas.

Assim, o Quadro 6 apresenta a evolução do número total de investigadores no período 1995-2017 bem como os setores que a desenvolvem.

Dos valores do Quadro 6 pode perceber-se, nomeadamente:

- o crescimento contínuo do número de investigadores no período, ainda que se perceba alguma irregularidade de crescimento nos últimos anos; de destacar que a tendência crescente parece ser uma realidade a partir de 2015 acompanhando a evolução anteriormente percebida quer do número de estudantes quer do número de diplomados;

- a quebra registada do número de investigadores, quer no setor Estado, quer nas Instituiçóes Privadas Sem Fins Lucrativos, par- 


\begin{tabular}{|c|c|c|c|c|c|}
\hline Anos & Total (No) & $\begin{array}{c}\text { Empresas } \\
(\text { No) }\end{array}$ & Estado (No) & $\begin{array}{c}\text { Instituiçóes } \\
\text { de Ensino } \\
\text { Superior (No) }\end{array}$ & $\begin{array}{l}\text { Instituiçóes } \\
\text { Privadas sem } \\
\text { fins Lucrati- } \\
\quad \text { vos (No) }\end{array}$ \\
\hline 1995 & $11.599,2$ & $1.075,5$ & $2.740,7$ & $5.850,1$ & $1.932,9$ \\
\hline 1997 & $13.642,3$ & $1.192,8$ & $2.929,5$ & $7.475,1$ & $2.044,9$ \\
\hline 1999 & $15.751,6$ & $1.994,3$ & $3.444,9$ & $8.242,5$ & $2.069,9$ \\
\hline 2001 & $17.725,1$ & $2.721,9$ & $3.646,4$ & $8.941,6$ & $2.415,2$ \\
\hline 2003 & $20.242,0$ & $3.793,9$ & $3.439,6$ & $10.062,4$ & $2.946,1$ \\
\hline 2005 & $21.126,3$ & $4.013,6$ & $3.337,6$ & $10.956,4$ & $2.818,7$ \\
\hline 2007 & $28.175,9$ & $8.477,0$ & $3.158,7$ & $13.113,9$ & $3.426,3$ \\
\hline 2008 & $40.408,0$ & $10.311,5$ & $3.202,8$ & $23.138,4$ & $3.755,2$ \\
\hline 2009 & $39.834,1$ & $10.160,0$ & $2.764,7$ & $23.242,1$ & $3.667,3$ \\
\hline 2010 & $41.523,4$ & $10.571,8$ & $2.440,0$ & $23.858,5$ & $4.653,1$ \\
\hline 2011 & $44.056,0$ & $12.198,2$ & $2.531,4$ & $23.754,4$ & $5.572,0$ \\
\hline 2012 & $42.498,2$ & $11.931,1$ & $1.682,2$ & $23.824,8$ & $5.060,1$ \\
\hline 2013 & $37.813,4$ & $10.024,8$ & $1.386,4$ & $25.760,1$ & 642,1 \\
\hline 2014 & $38.155,4$ & $11.203,2$ & $1.447,5$ & $24.977,6$ & 527,2 \\
\hline 2015 & $38.671,3$ & $11.784,3$ & $1.351,2$ & $25.043,2$ & 492,6 \\
\hline 2016 & $41.349,4$ & $13.425,9$ & $1.340,0$ & $26.105,7$ & 477,8 \\
\hline $2017\left(^{*}\right)$ & $44.321,8$ & $14.948,4$ & $1.453,3$ & $27.434,7$ & 485,5 \\
\hline
\end{tabular}

Quadro 6: Número de Investigadores por Setores de Execução, em Portugal, 1995-2017

(*) Previsão

Fonte: Elaboração própria - dados obtidos em Pordata (2018).

ticularmente nos últimos anos, em virtude dos cortes no investimento público;

- a participaçáo crescente das empresas privadas no emprego de investigadores, particularmente nos últimos anos, evidenciando uma alteração do paradigma anterior da maior participação do Estado na investigação científica; 
- a participação crescente, ainda que irregular, das instituiçôes de ensino superior que, desde sempre foram as entidades onde mais se faz investigação quer por obrigaçóes da carreira académica quer pelo facto de as atividades de extensão-serviços à comunidade serem parte da missão das universidades.

\begin{tabular}{|c|c|c|c|c|}
\hline Anos & $\begin{array}{c}\text { Empresas } \\
(\%)\end{array}$ & Estado (\%) & $\begin{array}{c}\text { Instituiçóes do } \\
\text { Ensino Superior } \\
(\%)\end{array}$ & $\begin{array}{c}\text { Instituiçóes } \\
\text { Particulares sem } \\
\text { fins lucrativos (\%) }\end{array}$ \\
\hline 1995 & 9,3 & 23,6 & 50,4 & 16,7 \\
\hline 2001 & 15,4 & 20,6 & 50,4 & 13,6 \\
\hline 2005 & 19,0 & 15,8 & 51,9 & 13,3 \\
\hline 2010 & 25,5 & 7,9 & 57,3 & 9,3 \\
\hline 2015 & 30,5 & 3,5 & 64,8 & 1,3 \\
\hline $2017\left(^{*}\right)$ & 33,7 & 3,3 & 61,9 & 1,1 \\
\hline
\end{tabular}

Quadro 7: Investigadores por Setores de Execução, em Portugal, 19952017, em percentagem

(*) Previsão

Fonte: Elaboração própria - dados obtidos em Pordata (2018).

O Quadro 7 destaca de forma elucidativa o papel das empresas e das instituiçôes de ensino superior no emprego científico.

Como se pode verificar, o ensino superior é o maior empregador de investigadores, vendo o seu papel crescendo ao longo do período; inversamente, o Estado vê o seu papel a diminuir de forma intensa ao mesmo tempo que se assiste ao crescimento do papel que a investigaçáo assume no mundo empresarial.

A evolução positiva do número de investigadores acima registada, independentemente do seu setor de execução, deverá ter contrapartida na atividade de investigação propriamente dita, a qual é dada a conhecer ao público através de diversas dimensóes e indicadores, nomeadamente através do número de publicaçốes científicas. Observe-se, neste âmbito, o Quadro 8. 


\begin{tabular}{|c|c|c|c|c|c|}
\hline Anos & $\begin{array}{c}\text { Total de } \\
\text { Publicaçóes (No) }\end{array}$ & $\begin{array}{c}\text { Artigos } \\
(\mathbf{N} \text { ) }\end{array}$ & $\begin{array}{c}\text { Resumos de } \\
\text { Comunicaçóes (No) }\end{array}$ & $\begin{array}{c}\text { Atas } \\
(\mathbf{N})\end{array}$ & $\begin{array}{c}\text { Outros } \\
(\mathbf{N})\end{array}$ \\
\hline $\mathbf{1 9 9 5}$ & 2.404 & 1.581 & 191 & 425 & 207 \\
\hline $\mathbf{1 9 9 6}$ & 2.699 & 1.904 & 151 & 530 & 114 \\
\hline $\mathbf{1 9 9 7}$ & 3.170 & 2.193 & 251 & 608 & 118 \\
\hline $\mathbf{1 9 9 8}$ & 3.674 & 2.422 & 320 & 781 & 151 \\
\hline $\mathbf{1 9 9 9}$ & 4.104 & 2.989 & 365 & 555 & 195 \\
\hline $\mathbf{2 0 0 0}$ & 4.474 & 3.215 & 350 & 667 & 242 \\
\hline $\mathbf{2 0 0 1}$ & 4.874 & 3.548 & 386 & 713 & 227 \\
\hline $\mathbf{2 0 0 2}$ & 5.537 & 3.964 & 530 & 757 & 286 \\
\hline $\mathbf{2 0 0 3}$ & 6.130 & 4.451 & 536 & 877 & 266 \\
\hline $\mathbf{2 0 0 4}$ & 6.942 & 5.020 & 805 & 806 & 311 \\
\hline $\mathbf{2 0 0 5}$ & 7.476 & 5.270 & 872 & 962 & 372 \\
\hline $\mathbf{2 0 0 6}$ & 9.164 & 6.481 & 1.144 & 1.089 & 450 \\
\hline $\mathbf{2 0 0 7}$ & 10.013 & 6.346 & 1.319 & 1.812 & 536 \\
\hline $\mathbf{2 0 0 8}$ & 11.950 & 7.437 & 1.720 & 1.980 & 813 \\
\hline $\mathbf{2 0 0 9}$ & 13.173 & 8.328 & 1.768 & 2.188 & 889 \\
\hline $\mathbf{2 0 1 0}$ & 14.403 & 9.077 & 2.147 & 2.099 & 1.080 \\
\hline $\mathbf{2 0 1 1}$ & 15.518 & 10.277 & 1.955 & 2.080 & 1.206 \\
\hline $\mathbf{2 0 1 2}$ & 17.631 & 11.497 & 2.310 & 2.464 & 1.360 \\
\hline $\mathbf{2 0 1 3}$ & 19.616 & 12.747 & 2.532 & 2.776 & 1.561 \\
\hline $\mathbf{2 0 1 4}$ & 20.421 & 12.962 & 2.399 & 3.355 & 1.705 \\
\hline $\mathbf{2 0 1 5}$ & 21.333 & 13.452 & 2.195 & 3.772 & 1.914 \\
\hline & & & & \\
\hline
\end{tabular}

Quadro 8: Publicaçóes Científicas em Portugal, por tipo de documento, 1995-2015

Fonte: Elaboração própria - dados obtidos em Pordata (2018).

Os dados apresentados no Quadro 8 testemunham bem a evolução fortemente positiva da produção científica nacional. Em 20 anos, o número de publicaçóes científicas quase decuplicou. Este dinamismo da produção científica do país sai mais reforçado quando se percebe que a maior parte das publicaçóes diz respeito a artigos e em atas de eventos científicos, considerando que estes tipos de publicaçáo são extremamente exigentes 
não só no que se refere à qualidade da publicação como à dificuldade de os investigadores dos pequenos países penetrarem o "mercado científico internacional".

Para uma melhor constatação deste progresso, observe-se o Quadro 9, que evidencia o peso de cada tipo de publicação no total das publicaçóes, no período 1995-2015.

\begin{tabular}{|c|c|c|c|c|}
\hline Anos & Artigos (\%) & $\begin{array}{c}\text { Resumos de } \\
\text { comunicaçōes (\%) }\end{array}$ & Atas (\%) & Outros (\%) \\
\hline 1995 & 65,8 & 7,9 & 17,7 & 8,6 \\
\hline 2000 & 71,9 & 7,8 & 14,9 & 5,4 \\
\hline 2005 & 70,5 & 11,7 & 12,9 & 5,0 \\
\hline 2010 & 63,0 & 14,9 & 14,6 & 7,5 \\
\hline 2015 & 63,1 & 10,3 & 17,7 & 9,0 \\
\hline
\end{tabular}

Quadro 9: Publicaçóes Científicas em Portugal, por tipo de documento, 1995-2015, em percentagem

Fonte: Elaboração própria - dados obtidos em Pordata (2018).

De igual modo, o dinamismo da investigação científica do país mede-se, também, pelo número de citações de publicações nacionais bem como pela sua internacionalização que pode ser medida pelo número de publicaçóes realizadas em coautoria de investigadores nacionais e internacionais. Observe-se o Quadro 10.

Os valores do Quadro 10 testemunham bem o crescimento do número de citaçóes de publicaçôes de autores nacionais. Por outro lado, a evolução do número de publicaçóes em coautoria com instituiçôes de outros países, que mais que decuplicou em 20 anos, testemunha bem a internacionalização da investigação científica portuguesa e o dinamismo do setor. Observe-se o Quadro 11 que apresenta o peso do número de citaçóes e de citaçóes em coautoria no total das citaçóes científicas.

Dos valores do Quadro 11, destaque-se o progressivo crescimento das citaçóes de publicaçóes em coautoria com instituiçóes de outros países revelando bem o crescimento da internacionalizaçáo da investigação científica portuguesa. 


\begin{tabular}{|c|c|c|c|}
\hline Anos & $\begin{array}{c}\text { Total de } \\
\text { Publicaçôes (No) }\end{array}$ & $\begin{array}{c}\text { Publicaçóes } \\
\text { Citadas (No) }\end{array}$ & $\begin{array}{c}\text { Publicaçóes em coautoria com } \\
\text { instituiçôes de outros países } \\
\text { (No) }\end{array}$ \\
\hline $\mathbf{1 9 9 5}$ & 2.404 & 1.749 & 827 \\
\hline $\mathbf{1 9 9 6}$ & 2.699 & 1.988 & 982 \\
\hline $\mathbf{1 9 9 7}$ & 3.170 & 2.313 & 1.140 \\
\hline $\mathbf{1 9 9 8}$ & 3.674 & 2.593 & 1.314 \\
\hline $\mathbf{1 9 9 9}$ & 4.104 & 3.093 & 1.638 \\
\hline $\mathbf{2 0 0 0}$ & 4.474 & 3.422 & 1.749 \\
\hline $\mathbf{2 0 0 1}$ & 4.874 & 3.768 & 2.022 \\
\hline $\mathbf{2 0 0 2}$ & 5.537 & 4.206 & 2.265 \\
\hline $\mathbf{2 0 0 3}$ & 6.130 & 4.611 & 2.538 \\
\hline $\mathbf{2 0 0 4}$ & 6.942 & 5.255 & 2.969 \\
\hline $\mathbf{2 0 0 5}$ & 7.476 & 5.583 & 3.157 \\
\hline $\mathbf{2 0 0 6}$ & 9.164 & 6.804 & 3.844 \\
\hline $\mathbf{2 0 0 7}$ & 10.013 & 7.129 & 3.908 \\
\hline $\mathbf{2 0 0 8}$ & 11.950 & 8.460 & 4.676 \\
\hline $\mathbf{2 0 0 9}$ & 13.173 & 9.358 & 5.166 \\
\hline $\mathbf{2 0 1 0}$ & 14.403 & 10.062 & 5.759 \\
\hline $\mathbf{2 0 1 1}$ & 15.518 & 11.063 & 6.690 \\
\hline $\mathbf{2 0 1 2}$ & 17.631 & 12.167 & 7.534 \\
\hline $\mathbf{2 0 1 3}$ & 19.616 & 12.998 & 8.535 \\
\hline $\mathbf{2 0 1 4}$ & 20.421 & 12.322 & 9.570 \\
\hline $\mathbf{2 0 1 5}$ & 21.333 & 9.828 & 10.582 \\
\hline & & & \\
\hline
\end{tabular}

Quadro 10: Publicações Científicas em Portugal, 1995-2015

Fonte: Elaboração própria - dados obtidos em Pordata (2018).

\begin{tabular}{|c|c|c|c|}
\hline Anos & $\begin{array}{c}\text { Total de citaçóes } \\
\text { (No) }\end{array}$ & $\begin{array}{c}\text { Publicaçóes } \\
\text { citadas (\%) }\end{array}$ & $\begin{array}{c}\text { Publicaçóes em coautoria com } \\
\text { instituiçóes de outros países } \\
(\%)\end{array}$ \\
\hline 1995 & 2576 & 67,9 & 32,1 \\
\hline 2000 & 5171 & 66,2 & 33,8 \\
\hline 2005 & 8740 & 63,9 & 36,1 \\
\hline 2010 & 15821 & 63,6 & 36,4 \\
\hline 2015 & 20410 & 48,2 & 51,8 \\
\hline
\end{tabular}

Quadro 11: Publicaçóes Científicas em Portugal, 1995-2015, em percentagem do total

Fonte: Elaboração própria - dados obtidos em Pordata (2018). 


\subsection{A investigaçáo científica portuguesa no contexto internacional}

O dinamismo do setor científico português dos últimos anos tem, naturalmente, reflexos em termos internacionais. Se, no Quadro 11 já foi possível perceber esse dinamismo bem como o processo de internacionalização da produção científica do país através da produção em coautoria de investigadores portugueses com investigadores de outros países, esse dinamismo também é visível quando se analisa o crescimento dos sistemas científicos no quadro internacional.

Observe-se os valores do Quadro 12 que apresenta os países cuja produção científica medida pelo número de artigos publicados em revistas científicas conheceu um crescimento anual acima dos $8 \%$.

\begin{tabular}{|c|c|c|c|}
\hline \multirow{2}{*}{ Países } & \multicolumn{2}{|c|}{ Artigos em Revistas Científicas (No) } & Taxa de Variação Média \\
\cline { 2 - 4 } & $\mathbf{1 9 9 5}$ & $\mathbf{2 0 1 1}$ & Anual (1995-2011) \\
\hline Irão & 280 & 8176 & $23,5 \%$ \\
\hline China & 9061 & 89894 & $15,4 \%$ \\
\hline Tunísia & 143 & 1016 & $13 \%$ \\
\hline Coreia do Sul & 3803 & 25593 & $12,7 \%$ \\
\hline Tailândia & 340 & 2304 & $12,7 \%$ \\
\hline Malásia & 366 & 2092 & $11,5 \%$ \\
\hline Turquia & 1715 & 8328 & $10,4 \%$ \\
\hline Portugal & 990 & 4626 & $10,1 \%$ \\
\hline Paquistão & 313 & 1268 & $9,1 \%$ \\
\hline Singapura & 1141 & 4543 & $9 \%$ \\
\hline Brasil & 3436 & 13148 & $8,7 \%$ \\
\hline
\end{tabular}

Quadro 12: Sistemas Nacionais de Ciência com crescimento médio mais rápido, 1995-2011

Fonte: Marginson (2016).

De acordo com os estudos de Marginson (2016), entre 1995 e 2011 a taxa de variaçáo média anual da produção científica portuguesa situou-se nos $10,1 \%$, colocando o sistema científico português em $8^{\circ}$ lugar, à frente dos sistemas nacionais de ciência da generalidade dos países desenvolvidos. 
Todavia, se dermos atenção ao período mais recente de 20062016, e também em conformidade com Marginson (2018), a taxa de variação média anual dos artigos publicados em revistas científicas, aquela taxa desce para os 6,8\% mas, ainda assim, bem superior à taxa homóloga relativa aos valores mundiais $(3,9 \%)$, conforme se pode observar no Quadro 13.

\begin{tabular}{|c|c|c|c|}
\hline \multirow{2}{*}{ Países } & \multicolumn{2}{|c|}{ Artigos em Revistas Científicas (No) } & \multirow{2}{*}{$\begin{array}{c}\text { Taxa de Variaçáo } \\
\text { Média Anual } \\
(2006-2016)\end{array}$} \\
\hline & 2006 & 2016 & \\
\hline Malásia & 3230 & 20332 & $20,2 \%$ \\
\hline Irão & 10073 & 40974 & $15,1 \%$ \\
\hline Roménia & 3523 & 10194 & $11,2 \%$ \\
\hline Índia & 38590 & 110320 & $11,1 \%$ \\
\hline Egipto & 3958 & 10807 & $10,6 \%$ \\
\hline China & 189760 & 426165 & $8,4 \%$ \\
\hline África do Sul & 5636 & 11881 & $7,7 \%$ \\
\hline Rússia & 29369 & 59134 & $7,2 \%$ \\
\hline Portugal & 7136 & 13773 & $6,8 \%$ \\
\hline Brasil & 28160 & 53607 & $6,6 \%$ \\
\hline MUNDO & 1.567 .422 & 2.295 .608 & $3,9 \%$ \\
\hline
\end{tabular}

Quadro 13: Sistemas Nacionais de Ciência com crescimento médio mais rápido, com mais de 10000 publicaçóes em 2016, 2006-2016

Fonte: Marginson (2018).

De destacar, ainda, que o sistema científico português continua no conjunto dos 10 sistemas científicos de crescimento mais rápido do mundo, situando-se em $9^{\circ}$ lugar, com uma taxa de variação média anual muito superior à sua homóloga quando se consideram países mais desenvolvidos como a Dinamarca (4,7\%), a Itália (3,3\%), a Alemanha (2,0\%), a Holanda $(2,0 \%)$ a Suécia $(1,8 \%)$, a França $(1,1 \%)$, o Reino Unido (1\%) ou os EUA (0,7\%). 


\section{Financiamento da educação e da investigação científica}

Uma das questóes que se colocam ao decisor político é, sempre, a do financiamento. Como financiar determinada política social é, certamente, um dos problemas mais complexos para os governantes, dado que desse financiamento depende a implementação de uma medida de política.

Num país com uma enorme despesa pública e dependente do exterior como Portugal, a questão do financiamento é, definitivamente, um grave problema a resolver. E é mais grave quando o investimento é sobre bens ou serviços cujos resultados só são percebidos a longo prazo. Assim acontece com serviços como a segurança, a saúde ou a educação que, em tempos de crise, têm tendência para ser perspetivados como despesas e não como investimento de que decorre, em geral, o seu subfinanciamento (MUCHARREIRA et al., 2019a; MUCHARREIRA et al., 2019b).

Neste quadro, não espanta que as despesas em educação sejam preteridas quando é necessário ratear os recursos existentes, particularmente em tempo de depressão e crise económica. É exatamente isto que tem vindo a acontecer em Portugal com a prestação de serviços públicos, incluindo a educação.

O Quadro 14 informa-nos sobre o financiamento do ensino superior público em Portugal e enquadra-o em termos internacionais.

\begin{tabular}{|c|c|c|c|}
\hline Anos & Portugal (\%) & Média OCDE (\%) & UE-21 (\%) \\
\hline 1995 & 96,5 & 76,7 & 86 \\
\hline 2005 & 68 & 70 & 80 \\
\hline 2008 & 62 & 70 & 80 \\
\hline 2011 & 69 & 70 & 80 \\
\hline 2013 & 58 & 71 & 80 \\
\hline 2014 & 62 & 70 & 78 \\
\hline
\end{tabular}

Quadro 14: Peso relativo dos Recursos Públicos no Orçamento das Instituiçóes Públicas de Ensino Superior, Portugal, UE e OCDE, 1995-2014

Fonte: OCDE (2017). 
O que poderá concluir-se desde logo é o forte desinvestimento que sucessivos governos têm realizado no ensino superior.

Como pode observar-se, a quebra da participação do Estado no orçamento das instituiçôes públicas de ensino superior em Portugal foi brutal e muito maior do que o ocorrido, em média, nos países da UE e da OCDE, organizaçóes que incluem países mais desenvolvidos do que Portugal.

A situaçáo que o Quadro 14 retrata é tanto mais grave quanto é certo que:

- as despesas públicas em educação em percentagem do PIB, sempre baixas, também têm diminuído fortemente, como se pode verificar em PORDATA (2019, última atualização em 3 de julho): 4,8\% do PIB em 2000; 3,7\% do PIB, em 2018;

- a despesa pública em investigação (somatório das despesas do Estado e das instituiçôes públicas de ensino superior) não atinge, sequer, os $1 \%$ do PIB, como pode verificar.se em PORDATA (2019, última atualização em 23 de junho): 0,80\% do PIB, em 2009; 0,69\% do PIB, em 2018.

\section{Consideraçóes finais}

O exposto, dá a conhecer um país que, nas últimas décadas, tentou "apanhar" os países mais desenvolvidos, quer no que respeita a procura de educação, nomeadamente de nível superior, quer no que respeita o número de diplomações ou o sistema de ciência do país.

Indubitavelmente, a democratização do país trouxe mudanças significativas na "educação", aproximando-se a situação de Portugal da situação que apresentam países mais desenvolvidos, democracias consolidadas cujo investimento em educaçâo e investigação remonta a finais do século XIX, princípio do século XX.

Pode, pois afirmar-se que a "juventude" da democracia portuguesa não tem constituído obstáculo ao desenvolvimento do sistema científico educação e investigação - do país. O Portugal democrático é, certamente, um caso de sucesso. 
E é por ser um caso de sucesso que não podemos deixar de questionar se o caminho percorrido não poderia já ser mais longo e consolidado, se houvesse uma vontade maior por parte do poder político no desenvolvimento do sistema científico português.

De facto, a evoluçáo registada tem sido acompanhada, no início da década em curso, por medidas de política de financiamento da educação, nomeadamente do ensino superior e da investigação, fortemente restritivas.

Em conclusão, podemos afirmar que Portugal tem feito um enorme esforço no sentido do desenvolvimento da educação e da investigação cujos resultados não são, ainda, apesar de tudo, suficientes para o país "apanhar" os seus parceiros mais desenvolvidos, situação que exige maiores níveis de investimento no setor por parte do Estado.

\section{Referências}

ANTUNES, Marina Godinho; MUCHARREIRA, Pedro Ribeiro; JUSTINO, Maria do Rosário; TEXEIRA QUIRÓS, Joaquín. A Implementação da TQM nas Instituiçôes de Ensino Superior Portuguesas - proposta de um modelo de investigaçáo. In: Livro de Atas do $8^{\circ}$ Conferência da FORGES - O Papel da Garantia da Qualidade na Gestão do Ensino Superior: Desafios, Desenvolvimentos e Tendências. Lisboa: Instituto Politécnico de Lisboa, 2018.

BARRETO, António. A Situação Social em Portugal, 1960-1995. Lisboa: Imprensa de Ciências Sociais, 1996.

BAUDELOT, Christian; ESTABLET, Roger. L'école capitaliste en France. Paris: Maspero, 1971.

BAUDELOT, Christian; ESTABLET, Roger. L'école primaire divise. Paris: Maspero, 1977. BOUDON, Raymond. L'inégalité des chances. La mobilité sociale dans les sociétés industrielles. Paris: Colin, 1973.

BOURDIEU, Pierre; PASSERON, Jean-Claude. Les héritiers. Paris: Les Éditions Minuit, 1964.

BOURDIEU, Pierre; PASSERON, Jean-Claude. La reproduction. Paris: Les Éditions Minuit, 1970.

CABRITO, Belmiro Gil. El proceso de Bolonia: desarrollo de las populaciones o la respuesta a los imperativos economicos. In: Actas das XIV Jornadas de la Asociación de la Economía de la Educación. Oviedo: Universidad de Oviedo, p. 451-462, 2005.

CABRITO, Belmiro Gil; CERDEIRA, Luísa. The Bologna Process and the Privatization of Higher Education. In: International Technology, Education and Development Conference - INTED 2008 Proceedings. Valencia: IATED Academy, 2008. 
CABRITO, Belmiro Gil; CERDEIRA, Luísa. O Ensino Superior em Portugal: Evolução e Potencialidades. Humanidades \& Inovação, v. 5, n. 8, p. 7-19, 2018.

CABRITO, Belmiro Gil; CERDEIRA, Luísa; MACHADO, Maria de Lourdes; PATROCÍNIO, Tomás; MUCHARREIRA, Pedro Ribeiro. Higher Education in Portugal between 1995-2015 and possible futures. In: INTED 2019 Proceedings Exploring New Frontiers in Education. Valencia: IATED Academy, p. 9906-9911, 2019. CERDEIRA, Luísa. O Financiamento do Ensino Superior Português: a Partilha de Custos. Coimbra: Almedina, 2009.

LOPES, Margarida Chagas. Educação, desenvolvimento e conhecimento: novas roupagens da troca desigual sob a globalizaçáo. O caso da África Subsahariana. Lisboa: Fundação Calouste Gulbenkian e Ediçôes Tinta-da-China, 2013.

MARGINSON, Simon. The Dream is Over. The Crisis of Clark Kerr's Californian Idea of Higher Education. Berkeley: University of California Press, 2016.

MARGINSON, Simon. The new geo-politics of higher Education. Global cooperation, national competition and social inequality in the World-Class University (WCU) sector Working paper no34. University of Oxford, UK: Centre for Global Higher Education, 2018. MÓNICA, Maria Filomena. Educação e Sociedade no Portugal de Salazar. Lisboa: Presença, 1978.

MUCHARREIRA, Pedro Ribeiro; CABRITO, Belmiro Gil; CAPUCHA, Luís. Net costs of class-size reduction: the portuguese case. Cadernos de Pesquisa, v. 49, n. 172, p. 164-181, 2019a.

MUCHARREIRA, Pedro Ribeiro; CABRITO, Belmiro Gil; CAPUCHA, Luís. Impactos financeiros de uma política de redução do número de alunos por turma: o caso Português. Educação (UFSM), v. 44, n. 1, p. 1-20, 2019 b.

MUCHARREIRA, Pedro Ribeiro; CABRITO, Belmiro Gil; CERDEIRA, Luísa. A formação docente em Portugal: o papel das instituiçōes do ensino superior na formação dos educadores de infância e dos professores do ensino básico e secundário. In CABRITO, Belmiro; MACEDO, Jussara; CERDEIRA, Luísa (Orgs.). Ensino Superior no Brasil e em Portugal-atualidades, questóes e inquietaçóes. Lisboa: Educa, p. 207-226, 2018.

OCDE. Education at a glance. Paris: OEDC, 2017.

PORDATA. Estatísticas de Portugal-Base de Dados de Portugal Contemporâneo. Disponível em: https://www.pordata.pt/Portugal. Acesso em: 3 jul. 2019.

PSACHAROPOULOS, George; WOODHALL, Maureen. Education for development, an analysis of invest and choices. Washington, DC: Oxford University Press, 1985.

Recebido em I7 set. 20I9/ Aprovado em I7 dez. 2019

Para referenciar este texto:

CERDEIRA, L.; CABRITO, B. G.; MUCHARREIRA, P. R. O crescimento do ensino superior no portugal democrático: evolução da pós-graduação e da produção científica. EccoS - Revista Científica, São Paulo, n. 51, eI4974, out./dez. 2019.

Disponível em: https://doi.org/I0.5585/EccoS.n50.I4974. 